UDC 347.4

LBC 67.404 .2

\title{
NEGATIVE OBLIGATIONS IN THE CONTEXT OF THE REFORM OF THE RUSSIAN CIVIL LAW
}

\author{
Dmitriy B. Korotkov \\ Perm State National Research University, Perm, Russian Federation
}

Introduction. According to Section 6 of Article 393 of the Civil Code of the Russian Federation, in case of violation of obligations by the debtor on refraining from doing certain actions (negative obligation), the creditor, regardless of damages, is entitled to demand an appropriate preventive action if it does not contradict the essence of the obligation. In practice, there are questions about the relationship of this provision with Section 3 of Article 328 of the Civil Code. The purpose and objectives. The author aims to substantiate that the norm of Section 6 of Article 393 of the Civil Code of the Russian Federation should be applied taking into account Section 3 of Article 328 , according to which none of the parties of obligations under which the counter performance provides no right to demand on court performance, without giving due obligation from it for the other party. Otherwise, the debtor is obliged to refrain from certain actions, even if the lender does not fulfill its reciprocal obligation. Methods. We used scientific methods of cognition and special legal methods. Results. The study analyzed the doctrinal and normative sources of domestic and foreign law. Application of results. The results of the study can be applied in the judicial interpretation of norms of Section 6 of Article 393 of the Civil Code. Conclusion. The right binding imposition of legal relations of the debtor's unconditional obligation to refrain from certain actions, regardless of the performance or non-performance lender reciprocal obligation would be contrary to mutually binding obligations. The use of Section 6 of Article 393 of the Civil Code of the Russian Federation as a way to protect the violated rights of the creditor without examining the issue of the performance by the creditor of its reciprocal obligation will lead to infringement of the rights of the debtor in good faith and would deprive the latter method of self-defense rights under Articles 12, 14 of the Civil Code of the Russian Federation, as well as the possibility of failure to fulfill its reciprocal obligation to the moment of execution by the creditor of their obligations.

Key words: debtor, creditor, negative obligation, reciprocal obligation, improper performance of an obligation.

УДК 347.4

ББК 67.404 .2

\section{НЕГАТИВНЫЕ ОБЯЗАТЕЛЬСТВА В КОНТЕКСТЕ РЕФОРМЫ РОССИЙСКОГО ГРАЖДАНСКОГО ПРАВА}

\footnotetext{
Дмитрий Борисович Коротков

Пермский государственный национальный исследовательский университет, г. Пермь, Российская Федерация

Введение: согласно п. 6 ст. 393 ГК РФ в случае нарушения должником обязательства по воздержанию от совершения определенного действия (негативное обязательство) кредитор независимо от возмещения убытков вправе требовать пресечения соответствующего действия, если это не противоречит существу обязательства. На практике возникают вопросы о соотношении данной нормы с п. 3 ст. 328 ГК РФ. Цель и задачи: 으으을 то, что применять норму п. 6 ст. 393 ГК РФ следует с учетом положений п. 3 ст. 328 ГК РФ, 공 согласно которым ни одна из сторон обязательства, по условиям которого предусмотрено встречное исполнен нение, не вправе требовать по суду исполнения, не предоставив причитающегося с нее по обязательству другой стороне. В противном случае должник будет обязан воздерживаться от совершения определенных \% действий даже в том случае, если кредитор не исполняет своего встречного обязательства. Методы: автором применены общенаучные методы познания и специально-юридические методы исследования. В результате по. проведенного исследования были проанализированы доктринальные и нормативные источники отечественного и зарубежного права. Область применения результатов: они могут быть применены в ходе судебного
} 
толкования нормы п. 6 ст. 393 ГК РФ. Вывод: в двусторонне обязывающих правоотношениях наложение на должника безусловной обязанности по воздержанию от совершения определенного действия вне зависимости от исполнения или неисполнения кредитором своего встречного обязательства будет противоречить существу взаимообязывающего обязательства. Применение п. 6 ст. 393 ГК РФ как способа защиты нарушенных прав кредитора без исследования вопроса об исполнении самим кредитором своего встречного обязательства приведет к ущемлению прав добросовестного должника и лишит последнего способа самозащиты права, предусмотренного ст. 12, 14 ГК РФ, а также возможности отказа от исполнения встречного обязательства до момента исполнения кредитором своей части обязательства.

Ключевые слова: должник, кредитор, негативное обязательство, встречное обязательство, ненадлежащее исполнение обязательства.

\section{Введение}

Федеральным законом от 8 марта 2015 г. № 42-Ф3 внесены изменения в ст. 393 Гражданского кодекса РФ (далее - ГК РФ) в части появления в ней нового пункта 6 следующего содержания: в случае нарушения должником обязательства по воздержанию от совершения определенного действия (негативное обязательство) кредитор независимо от возмещения убытков вправе требовать пресечения соответствующего действия, если это не противоречит существу обязательства. Данное требование может быть предъявлено кредитором и в случае возникновения реальной угрозы нарушения такого обязательства.

На стадии становления правоприменительной практики в отношении данного положения закона среди участников гражданского оборота стали возникать вопросы о его соотношении с иными положениями ГК РФ, в частности, с п. 3 ст. 328 ГК РФ.

В настоящей статье нами будет предпринята попытка обосновать то, что применять норму п. 6 ст. 393 ГК РФ о последствиях неисполнения должником негативного обязательства следует с учетом положений п. 3 ст. 328 ГК РФ, согласно которым ни одна из сторон обязательства, по условиям которого предусмотрено встречное исполнение, не вправе требовать по суду исполнения, не предоставив причитающегося с нее по обязательству другой стороне. В противном случае должник может оказаться в патовой ситуации: он обязан будет воздерживаться от совершения определенных действий (негативного обязательства) даже в том случае, если кредитор не исполняет своего встречного обязательства.

\section{Системное толкование нормы п. 6 ст. 393 ГК РФ}

Для обоснования практической значимости поднятого вопроса о порядке и условиях применения нормы п. 6 ст. 393 ГК РФ приведем следующую ситуацию.

Допустим, сторонами, осуществляющими предпринимательскую деятельность, заключен агентский договор, по условиям которого принципал поручил, а агент принял на себя обязательство за вознаграждение совершать от своего имени, но за счет принципала юридические и иные действия, направленные на реализацию производимого принципалом товара (например, молочной продукции), а принципал обязался уплатить агенту вознаграждение за выполнение указанного поручения.

По условиям договора принципал обязался также воздерживаться от самостоятельной деятельности, направленной на реализацию производимой им продукции на территории действия агентского договора (например, территория Приволжского федерального округа России).

С учетом того, что производимая принципалом молочная продукция объективно не предполагает длительного срока хранения, стороны предусмотрели в агентском договоре в качестве одного из существенных условий обеспечение непрерывности продажи агентом производимой принципалом продукции по утвержденному сторонами графику (стороны согласовали объемы производства и корреспондирующие им объемы продажи).

Далее предположим, что агент реализовывал молочную продукцию принципала с систематическим отклонением от согласованного сторонами графика. Тогда, поскольку агентом систематически допускалось испол- 
Д.Б. Коротков. Негативные обязательства в контексте реформы российского гражданского права

нение обязательств с нарушением условий договора, принципал, исходя из встречности отношений и взаимности обязательств по агентскому договору, в соответствии со ст. 328 и 404 ГК РФ произвел частичную самостоятельную реализацию своей продукции. Указанные действия принципал объяснил необходимостью реализации скоропортящейся продукции под угрозой ее полной утраты.

Теперь разберем приведенный пример правоотношений сторон сквозь призму применения п. 6 ст. 393 ГК РФ о последствиях неисполнения должником негативного обязательства с учетом положений п. 3 ст. 328 ГК РФ.

В соответствии с п. 3 ст. 307 ГК РФ при установлении, исполнении обязательства и после его прекращения стороны обязаны действовать добросовестно, учитывая права и законные интересы друг друга, взаимно оказывая необходимое содействие для достижения цели обязательства, а также предоставляя друг другу необходимую информацию.

Указанная норма права обязывает сторону договора (в нашем случае - агента, действующего в интересах принципала) осуществлять свои права на наиболее выгодных для контрагента условиях и в соответствии с его указаниями. Иными словами, при нормальном осуществлении обязанностей и с учетом условий агентского договора агент применительно к положениям ст. 307 ГК РФ должен был реализовывать продукцию принципала по утвержденному сторонами графику.

Применяя норму п. 6 ст. 393 ГК РФ в отрыве от иных норм ГК РФ, агент может предъявить принципалу исковое требование о воздержании последним от реализации своего негативного обязательства, а именно запретить самостоятельную реализацию производимой продукции даже в том случае, если последний вынужден к такой реализации в силу виновного бездействия агента, который не исполняет свои встречные договорные обязательства и не реализует по установленному графику скоропортящуюся продукцию. При этом агент может ссылаться на то, что норма п. 6 ст. 393 ГК РФ сама по себе не предполагает необходимости установления виновности или невиновности поведения кредитора для обязания должника воздерживаться от реализации негативного обязательства.
Полагаем, что подобное толкование п. 6 ст. 393 ГК РФ не может быть признано правильным.

\section{Результаты}

Теоретико-доктринальное обоснование необходимости применения нормы п. 6 ст. 393 ГК РФ с учетом положений п. 3 ст. 328 ГК РФ видится нам следующим.

Негативные обязательства, несмотря на относительно недавнее закрепление в тексте ГК РФ, имеют длительную историю становления и применения.

Право Древнего Рима исходило из возможности возложить на должника обязанность воздерживаться в определенных случаях от совершения того или иного юридически значимого действия [4, с. 436].

Классики российской цивилистики также поддерживали концепцию существования обязательств с отрицательным содержанием. Например, О.С. Иоффе утверждал, что «негативное поведение (воздержание от совершения каких-либо действий) может явиться дополнением или следствием выполняемой должником активной функции» [5, с. 13]. Несмотря на то что в данном случае негативному обязательству отводится лишь вспомогательная функция, остается фактом то, что за подобными обязательствами признавалось место в системе обязательственного права.

Поддерживая концепцию негативных обязательств, М.М. Агарков указывал на имущественный субстрат данного обязательства $[1$, c. 42$]$. При этом отметим, что негативные обязательства в современном гражданском обороте с очевидностью могут носить и неимущественный характер (например, закрепление в договоре найма жилого помещения условия о воздержании нанимателя после определенного времени от производства бытовых работ, сопряженных с высоким уровнем шума). Указанного мнения придерживается также Ф.О. Богатырев [2].

Гражданское право зарубежных стран также признает институт негативных обязательств. Например, параграф 241 Германского гражданского уложения закрепляет «договор о воздержании от конкуренции», по условиям которого сторона обязуется воздерживаться от совершения действий, направлен- 
ных на ведение на определенной территории деятельности, аналогичной деятельности своего контрагента. Аналогичную позицию занимает французский законодатель. Так, ст. 1101 Французского гражданского кодекса определяет договор как соглашение, содержание которого могут формировать как позитивные действия, так и негативные обязательства.

Возвращаясь к анализу п. 6 ст. 393 ГК РФ, следует отметить, что комментаторы ГК РФ пока с осторожностью подходят к вопросу системного толкования данной нормы, преимущественно ограничиваясь анализом ее применения в ситуации, когда убытки кредитору реально причинены, и в ситуации, когда требование к должнику предъявляется до нарушения обязательства при возникновении реальной угрозы такого нарушения [3, с. 393]. Вопрос о соотношении п. 6 ст. 393 ГК РФ и п. 3 ст. 328 ГК РФ пока широко не освещается.

Следует обратить внимание на позицию, высказанную А.Г. Карапетовым, который для раскрытия конструкции исполнения должником негативного обязательства приводит пример, схожий с приведенным нами в настоящей статье. Ученый указывает: «Например, если эксклюзивный дистрибьютор перестает выплачивать иностранному поставщику автомобилей положенную оплату за отгруженные автомобили, было бы логично, если бы право давало поставщику право приостановить исполнение своего негативного обязательства воздержаться от поставок автомобилей на российский рынок через других посредников» [6, с. 101]. Мы поддерживаем предложенную постановку вопроса, однако предлагаем не ограничиваться в толковании заявленного правоприменения только существом негативного обязательства, а ставить вопрос о том, что п. 3 ст. 328 ГК РФ является общей нормой, относящейся ко всем видам обязательств. Следовательно, неисполнение кредитором своего встречного обязательства должно снимать с должника корреспондирующую обязанность воздержания от совершения определенного действия.

\section{Выводы}

В заключение рассмотрения вопроса о применении нормы п. 6 ст. 393 ГК РФ обозначим следующий вывод.
В двусторонне обязывающих (синаллагматических) правоотношениях наложение на должника безусловной обязанности по воздержанию от совершения определенного действия (негативное обязательство) вне зависимости от исполнения или неисполнения кредитором своего встречного обязательства будет противоречить существу взаимообязывающего обязательства. Следовательно, применение п. 6 ст. 393 ГК РФ как способа защиты нарушенных прав кредитора, без исследования вопроса об исполнении самим кредитором своего встречного обязательства, приведет к ущемлению прав добросовестного должника и лишит последнего прав, предоставленных ему законом, а именно способа самозащиты права, предусмотренного ст. 12, 14 ГК РФ, а также возможности отказа от исполнения встречного обязательства до момента исполнения кредитором своей части обязательства (п. 3 ст. 328 ГК РФ). Иная трактовка порядка применения п. 6 ст. 393 ГК РФ может, по нашему мнению, породить злоупотребление кредитором правом требования исполнения от контрагента при собственном недобросовестном бездействии (ст. 10 ГК РФ).

\section{СПИСОК ЛИТЕРАТУРЫ}

1. Агарков, М. М. Обязательство по советскому гражданскому праву / М. М. Агарков. - М. : Юридическое изд-во НКЮ СССР, 1940. - 192 с.

2. Богатырев, Ф. О. Обязательство воздерживаться от совершения какого-либо действия / Ф. О. Богатырев // Законодательство. - 2001 . № 5. - C. 15-20.

3. Гражданский кодекс Российской Федерации. Постатейный комментарий к разделу III «Общая часть обязательного права» / А. В. Барков, А. В. Габов, М. Н. Илюшина [и др.] ; под ред. Л. В. Санниковой. - М. : Статут, 2016. -622 с.

4. Дождев, Д. В. Римское частное право / Д. В. Дождев. - М. : Инфра-М, 1996. - 704 с.

5. Иоффе, О. С. Обязательственное право / О. С. Иоффе. - М. : Юридическая литература, 1975. $-880 \mathrm{c}$.

6. Карапетов, А. Г. Приостановление исполнения обязательства как способ защиты прав кредитора / А. Г. Карапетов. - М. : Статут, 2011. $239 \mathrm{c}$. 
Д.Б. Коротков. Негативные обязательства в контексте реформы российского гражданского права

\section{REFERENCES}

1. Agarkov M.M. Obyazatelstvo po sovetskomu grazhdanskomu pravu [Obligation under the Soviet Civil Law]. Moscow, Yurid. izd-vo NKYu SSSR, 1940. $192 \mathrm{p}$.

2. Bogatyrev F.O. Obyazatelstvo vozderzhivatsya ot soversheniya kakogo-libo deystviya [The Obligation to Refrain from Engaging in Any Act]. Zakonodatelstvo, 2001, no. 5, pp. 5-20.

3. Barkov A.V., Gabov A.V., Ilyushina M.N., eds. Grazhdanskiy kodeks Rossiyskoy Federatsii. Postateynyy kommentariy k razdelu III "Obshchaya chast obyazatelnogo prava" [The Civil Code of the Russian Federation. Commentaries to Section III "General Part of Obligations"]. Moscow, Statut Publ., 2016. $622 \mathrm{p}$.

4. Dozhdev D.V. Rimskoe chastnoe pravo [Roman Private Law]. Moscow, INFRA-M Publ., 1996. $704 \mathrm{p}$.

5. Ioffe O.S. Obyazatelstvennoe pravo [Liability Law]. Moscow Yurid. lit. Publ., 1975. 880 p.

6. Karapetov A.G. Priostanovlenie ispolneniya obyazatelstva kak sposob zashchity prav kreditora [Suspension of the Obligation as a Way to Protect the Rights of the Creditor]. Moscow, Statut Publ., 2011.239 p.

\section{Information About the Author}

Dmitriy B. Korotkov, Candidate of Juridical Sciences, Associate Professor, Department of Civil Law, Perm State National Research University, Bukireva St., 15, 614990 Perm, Russian Federation, korotkov-dmitry@mail.ru.

\section{Информация об авторе}

Дмитрий Борисович Коротков, кандидат юридических наук, доцент кафедры гражданского права, Пермский государственный национальный исследовательский университет, ул. Букирева, 15, 614990 г. Пермь, Российская Федерация, korotkov-dmitry@mail.ru. 